\title{
Resistivity imaging and self-potential applications in groundwater investigations in hard crystalline rocks
}

\author{
S.U.P. ${ }^{1}$ Jinadasa and R.P. de Silva ${ }^{2 *}$ \\ ${ }^{1}$ Oceanography Division, National Aquatic Resources Research and Development Agency, Crow Island, Colombo. \\ ${ }^{2}$ School of Architecture, Design \& Built Environment, Room 308, Waverly Building, City Compus, Nottingham Trent University, Burton Street, \\ Nottingham NG $4 B U$, UK.
}

Revised: 27 July 2008; Accepted: 19 September 2008

\begin{abstract}
Despite massive river diversion schemes there is a shortage of water in most areas of the dry zone of Sri Lanka. Therefore, prospecting for groundwater in the hard crystalline rocks is a top priority. A geological and geophysical study was therefore carried out to investigate groundwater accumulations in the hard rock terrain in Moneragala, using the resistivity imaging and self-potential techniques. This possibly is the first time that the above technique is used in the country, in prospecting for groundwater.
\end{abstract}

Interpretations using aerial photographs and geological maps carried out prior to the field survey indicate significant lineaments and fracture zones in the study area. These locations, which are favourable for groundwater accumulations, were tested using the resistivity imaging and self potential methods in 8 transects up to $200 \mathrm{~m}$ in length with an electrode spacing of $5 \mathrm{~m}$.

The results obtained show areas of low resistivities and negative self potential anomalies, which correlate well with the geological structures identified from maps or field observations. These are possibly areas with groundwater accumulations. More work, including bore holes are required to confirm the findings. However, this study shows that these simple methods show promise and may be used to improve accuracy to locate groundwater wells in the dry zone.

Keywords: Crystalline rocks, resistivity imaging, self potential, Sri Lanka.

\section{INTRODUCTION}

The amount of surface water available for domestic, industrial and agricultural use is insufficient to fulfil the current demand in the world. Therefore, exploration for groundwater (possibly with latest technology) is of vital importance. In Sri Lanka, previous groundwater exploration studies have concentrated mainly on the sedimentary basins and less on the hard rock terrain ${ }^{1}$ although more than $90 \%$ of the island is underlain by crystalline hard rocks. A few studies have been conducted on hard rocks for estimating recharge of agro wells in the dry zone $\mathrm{z}^{2-4}$, for the groundwater potential in the coconut triangle ${ }^{5}$ and in a study of the Kandy area ${ }^{6}$.

With the advances in technology, hydrogeologists and geophysicists resorted to geophysical methods such as very low frequency, direct- current resistivity sounding, resistivity imaging, self-potential (SP), electro kinetic and magnetic methods to locate groundwater. Although very low frequency surveys and resistivity methods are common and well-known, resistivity imaging, magnetic surveys, self-potential surveys and electro kinetic methods are still at experimental levels. Direct current resistivity sounding is not satisfactory for deep stratigraphical investigations (more than $100 \mathrm{~m}$ ) in hard rock terrain because polarization hinders the penetration efficiency of electricity through electrodes and results may hinder the efficiency of groundwater prospecting in dry metamorphic terrains. Very low frequency electromagnetic surveys are usually more useful in locating groundwater in deep fractures than the direct-current resistivity method ${ }^{7}$.

Resistivity imaging system (also called resistivity tomography system) uses 2D electrical imaging/ topography surveys to map areas with complex geology ${ }^{8}$. This kind of survey normally uses a large number of electrodes (may be 25 or more), connected to a multicore cable. The electrode spacing is normally a constant. A laptop computer together with electronic switching is used to automatically select the four relevant electrodes 
for each measurement. Results thus obtained are normally presented as resistivity $2 \mathrm{D}$ images with different colour combinations representing different resistivities as shown later under results. Typical values of resistivities include 5000 use same hyphen 1,000,000 ohm.m for granite, 1800 ohm.m for overburden soils and $10-100$ ohm.m for groundwater ${ }^{9}$.

The SP method is based on measuring the natural direct current potential between any two points on the ground $^{10}$. The potential differences are partly constant and partly fluctuating and are associated with electrical currents in the ground. Large anomalous potentials are often observed over sulphide and graphite ore bodies, magnetite and several other electrically conductive minerals ${ }^{11}$ and groundwater accumulations ${ }^{12,13}$. Selfpotential anomalies are also associated with water in subsurface structures and flow of water through the ground, where it is used extensively to detect seepage of water through dams ${ }^{14}$. The streaming self potential of groundwater is usually indicated as a negative anomaly in the profile ${ }^{15}$.

The study reports probably for the first time the application of both methods together for local groundwater exploration. However, limited amount of work has been conducted using resistivity imaging on thermal springs, archaeological sites and groundwater exploration investigations in Sri Lanka ${ }^{16}$. The results obtained by multi-electrode resistivity imaging and self potential surveys have been more than $70 \%$ successful in groundwater exploration surveys in the Kelani valley paleo alluvium basin. Nevertheless, the resistivity imaging and self potential survey results contradicted the results obtained from the archaeological sites at Anuradhapura ${ }^{16}$.

The overall objective of the investigation was to apply the resistivity imaging and self potential techniques along with aerial photographic and geological map interpretations for prospecting locations of groundwater accumulations in hard crystalline rocks in Sri Lanka.

\section{METHODS AND MATERIALS}

The location chosen for this study was Moneragala ( $6^{\circ} 52^{\prime} 0 \mathrm{~N}, 81^{\circ} 20^{\prime} 60 \mathrm{E}$, altitude $157 \mathrm{~m}$ ) in the Southeast of Sri Lanka as shown in Figure 1, where there is severe shortage of water, and no major rivers or river diversion schemes (even in the planning stage).

The major rock units in the study area belong to the Highland Complex and the Vijayan Complex as the study area overlies the boundary between these two rock units.
The major rock type in the study area is metamorphic gneiss. Other common rock types are biotite gneisses, hornblende biotite gneisses, migmatites, granites, and calc gneisses ${ }^{17}$. The field observations indicated that the area is covered by unconsolidated loose sediments except at a few rock outcrops.

As the regional geology and geomorphology are key indices in locating groundwater reserves in a given area, the geological maps, topographic maps and aerial photographs were studied prior to investigations to identify the most favourable sites for groundwater. The most probable areas of fracture zones, faults, drainages and lineaments were identified by interpretation of the above maps and images. The results are shown in the map in Figure 1.

To measure the self potential, a multi-meter with sufficiently high input impedance was connected to electrodes driven some $10-15 \mathrm{~cm}$ into the ground and read off. A normal potentiometer circuit was not used as it tends to reduce short and long wave telluric disturbances with a reduction in appropriate field measurements ${ }^{18}$. To avoid zero errors, one electrode was fixed whilst moving the other electrode. Both the resistivity imaging method and self potential method were applied in parallel at selected locations as shown in Figure 1. The resistivity imaging survey was carried out with $5 \mathrm{~m}$ electrode spacing and penetration up to $20 \mathrm{~m}$ instead of $10 \mathrm{~m}$ spacing, due to instrumentation malfunctioning in the field. A total number of eight resistivity imaging profiles were carried out together with eight parallel SP profiles as can be seen in Figure 1 in the study area.

The locations of the resistivity imaging and self potential surveys were decided using a Nav 5000 hand held Global Positioning System (GPS). The coordinates of starting and end points of the traverses were recorded for both resistivity imaging and self potential surveys.

\section{RESULTS AND DISCUSSION}

The results of faults, fracture zone and lineaments obtained from aerial photographs and geological / topographical map interpretations are indicated in Figure 1. Results obtained from resistivity imaging and self potential methods are shown in Figures 3 - 18. As can be seen from the resistivity images, a wide range of resistivities ranging from about 25 ohm.m to about 5000 ohm.m are shown on the resistivity image profiles, indicating areas of hard rocks (with a resistivity value approaching 5000 ohm.m) to areas of possible groundwater accumulations (with a resistivity of $10-100 \mathrm{ohm} . \mathrm{m}$ ). Self-potential surveys were conducted to compliment and confirm the results obtained from resistivity images. 
The resistivity image for transect $\mathrm{W}_{4} \mathrm{~W}_{1}$ shown in Figure 3 was conducted across the Mandappan Oya (stream). The results suggest a possible fault structure (Figure 3) as seen in the structural map of the area as well (Figure 1). Rocks with high resistivity were observed at upper left area of the profile (from a distance of $0 \mathrm{~m}$ to about 80 $\mathrm{m})$. These high resistivities are shown on the right side of Figure 3 at a depth of more than $40 \mathrm{~m}$ which suggests and Hoower ${ }^{19}$ suggest, steep SP gradients often indicate faults with accompanying movement of water and hence the SP anomalies in Figure 4 can be inferred as indicating groundwater accumulations. Geological maps, resistivity imaging and SP profiles all point to favourable conditions for groundwater. Therefore, in all probability this is a possible location for the existence of a good source of groundwater.

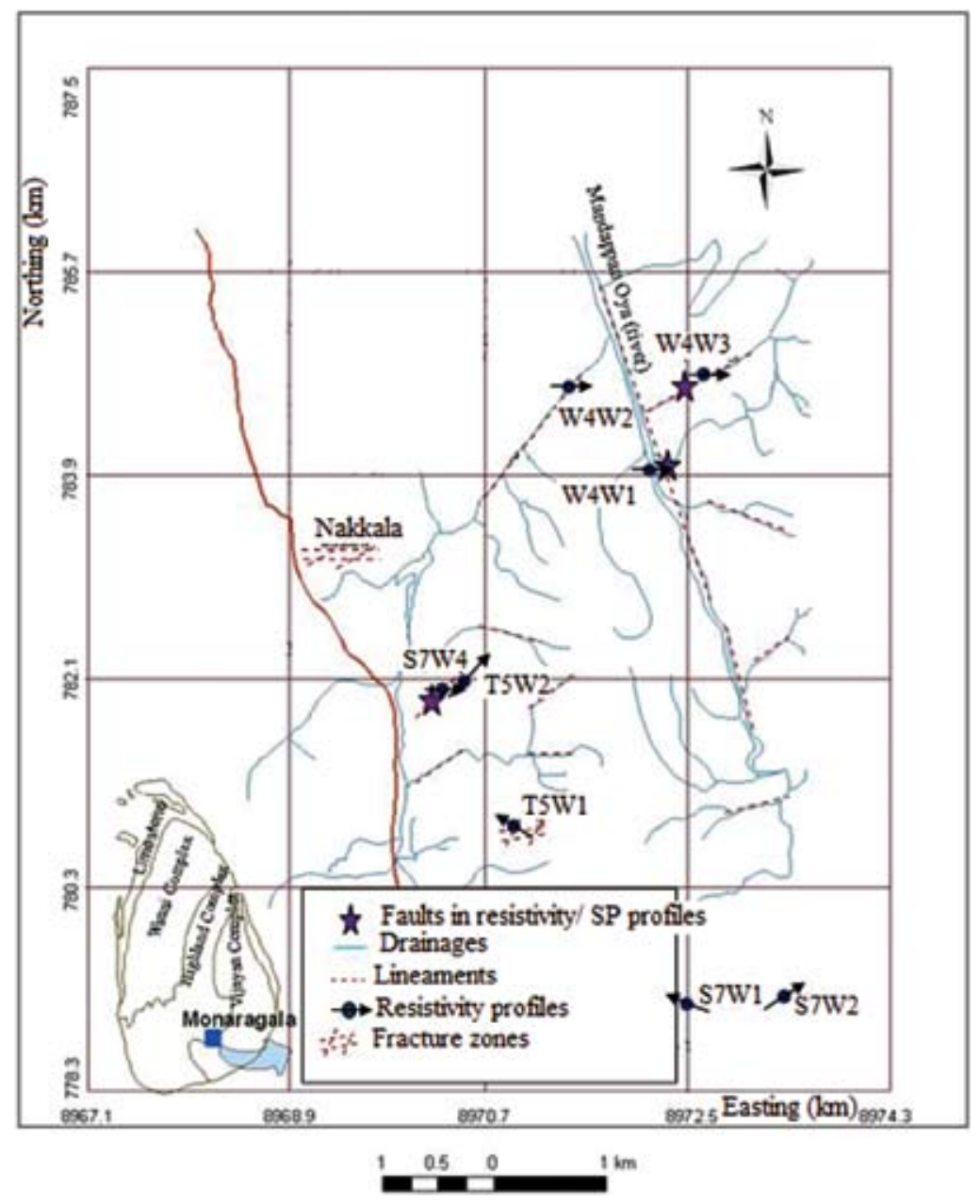

Figure 1: Survey locations of resistivity imaging and self-potential (Faults, lineaments and fracture zones identified by geological and topographic maps and aerial photographs are also shown. The grid lines are given as kilometres east of the Greenwich meridian and north of the equator.)

vertical displacement of the rocks with high resistivity along the fault plane. The low resistivities at the upper right area at a distance of about $180 \mathrm{~m}$ in the profile possibly suggest groundwater accumulations.

Figure 4 shows the parallel SP survey results on the same transect $\left(\mathrm{W}_{4} \mathrm{~W}_{1}\right)$ with a similar electrode configuration. SP anomalies show gradual decrease from high to low values at a distance of $50-200 \mathrm{~m}$. As Corwin
The resistivity image profile for transect $\mathrm{W}_{4} \mathrm{~W}_{2}$ shows significant, well-defined geological features (Figure 5). At a distance of about $160 \mathrm{~m}$, a possible fault approximately $60^{\circ}$ towards the upper right in the profile can be inferred. This fault was clearly seen along the branch of Madappan oya in the geological map (Figure 1). A low resistivity zone at a distance of about $140 \mathrm{~m}$ possibly indicates groundwater accumulation at a depth of $15 \mathrm{~m}$ from the surface. 


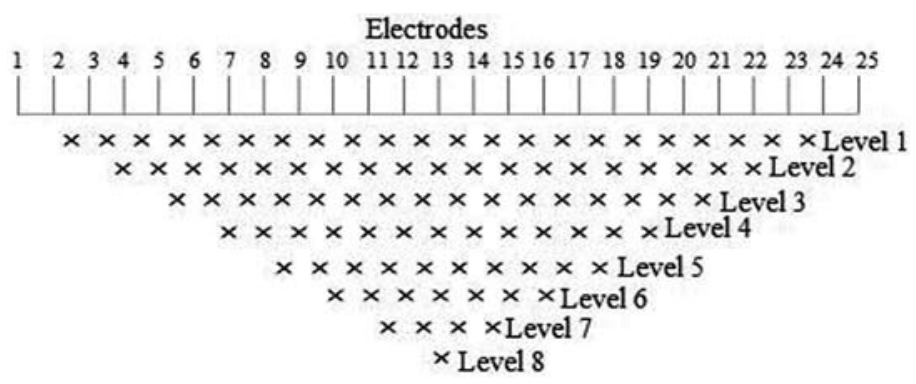

Figure 2: Electrode setup and measurement sequence for building up a pseudosection ${ }^{9}$

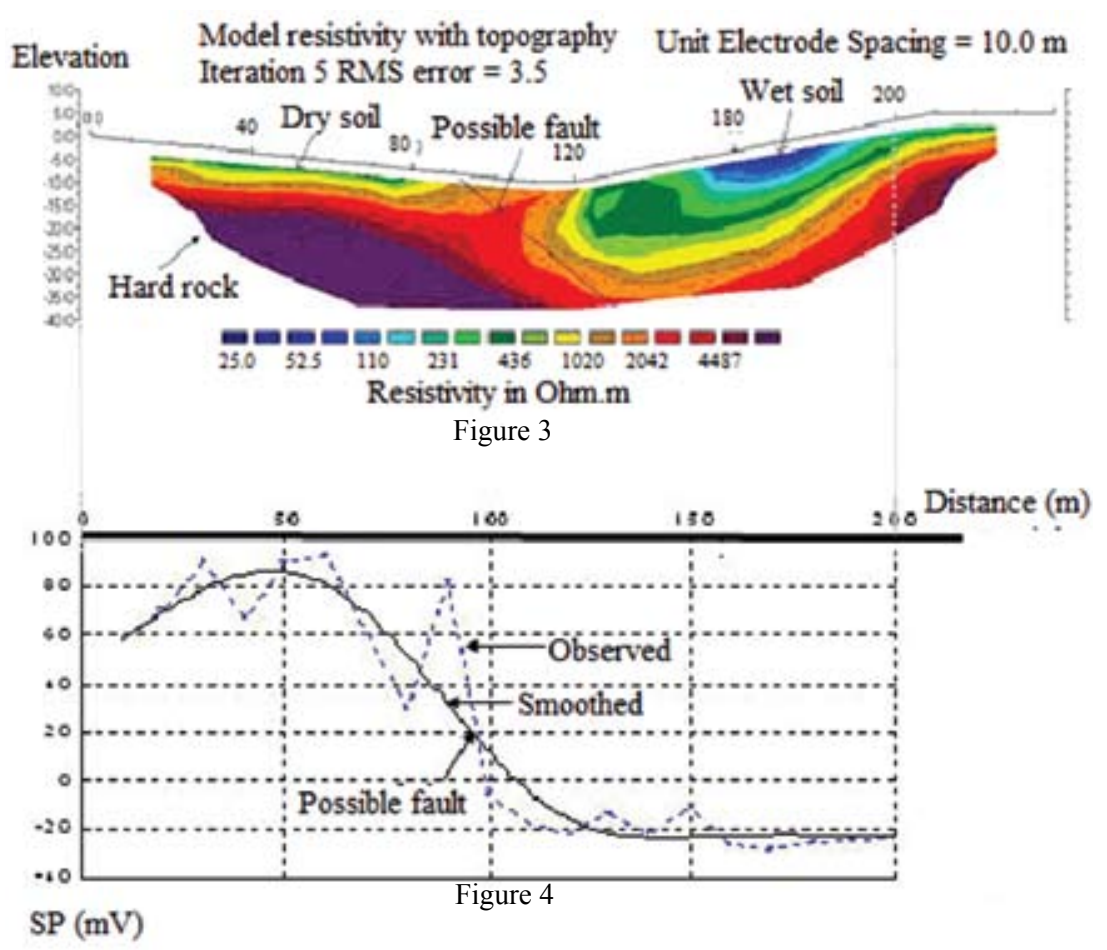

Figures 3 and 4: Resistivity image and SP survey profile respectively for transect $\mathrm{W}_{4} \mathrm{~W}_{1}$

Figure 6 shows the self-potential anomalies for transect $\mathrm{W}_{4} \mathrm{~W}_{2}$ where low values of anomalies could be noticed between $100 \mathrm{~m}$ to $150 \mathrm{~m}$ (indicated by a circle in Figure 6). This agrees well with the resistivity image identified geological structures in the same region and also with the aerial photograph identified fault.

The resistivity imaging profile for transect $\mathrm{W}_{4} \mathrm{~W}_{3}$ indicates a directional fault (Figure 7) below the $13^{\text {th }}$ electrode at a distance of about $120 \mathrm{~m}$. A directional fault was identified around the same location in the geological and structural map. Figure 8 (which shows the $\mathrm{SP}$ anomalies for transect $\mathrm{W}_{4} \mathrm{~W}_{3}$ ), indicates negative anomalies at the centre of the profile at a distance between 25-120 $\mathrm{m}$ thus tallying well with the low resistivity values of the resistivity image. It must be noted that water accumulations are not indicated near the probable fault, as it is unlikely that water will accumulate near the fault since it is almost a vertical one.

Transect $\mathrm{T}_{5} \mathrm{~W}_{1}$ was selected to investigate a structurally fractured zone in the area, as identified by aerial photographs. The resistivity image for the transect (Figure 9) has two high resistivity zones separated by low resistivities. The high resistivity zone on the left side of the profile is restricted to shallow depth, possibly representing a hard rock boulder overlying soils with low resistivity. The high resistivity zone on the right side of the profile at a horizontal distance of about $80-120 \mathrm{~m}$ stretches deeper, indicating a possible extension of the basement rocks. 
The low resistivity zone in Figure 9, sandwiched between two high resistivity zones, possibly indicates the existence of a weak geological structure, which is favourable for the accumulation of groundwater. Two negative SP anomalies between $20-80 \mathrm{~m}$ and after $120 \mathrm{~m}$ respectively correspond to the two low resistivity zones of the resistivity image for the transect.

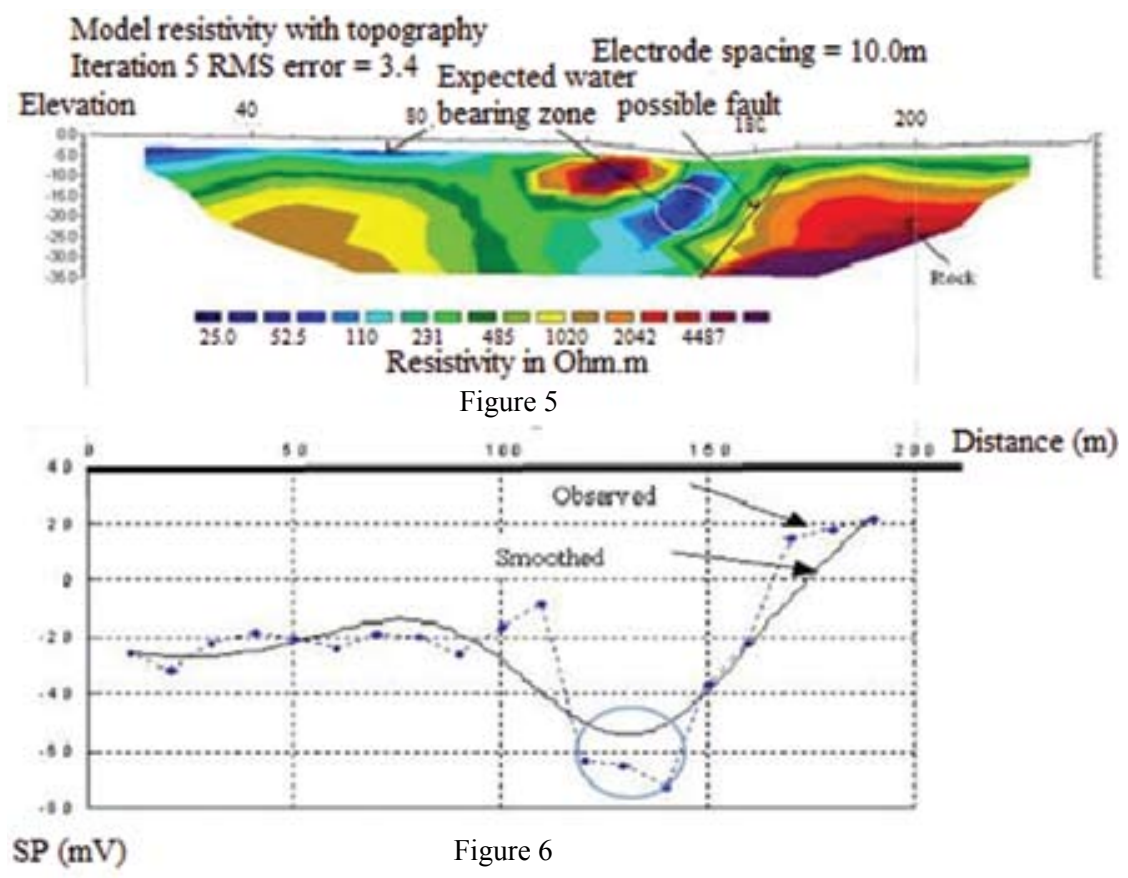

Figures 5 and 6: Resistivity image and SP survey profile respectively for transect $W_{4} W_{2}$

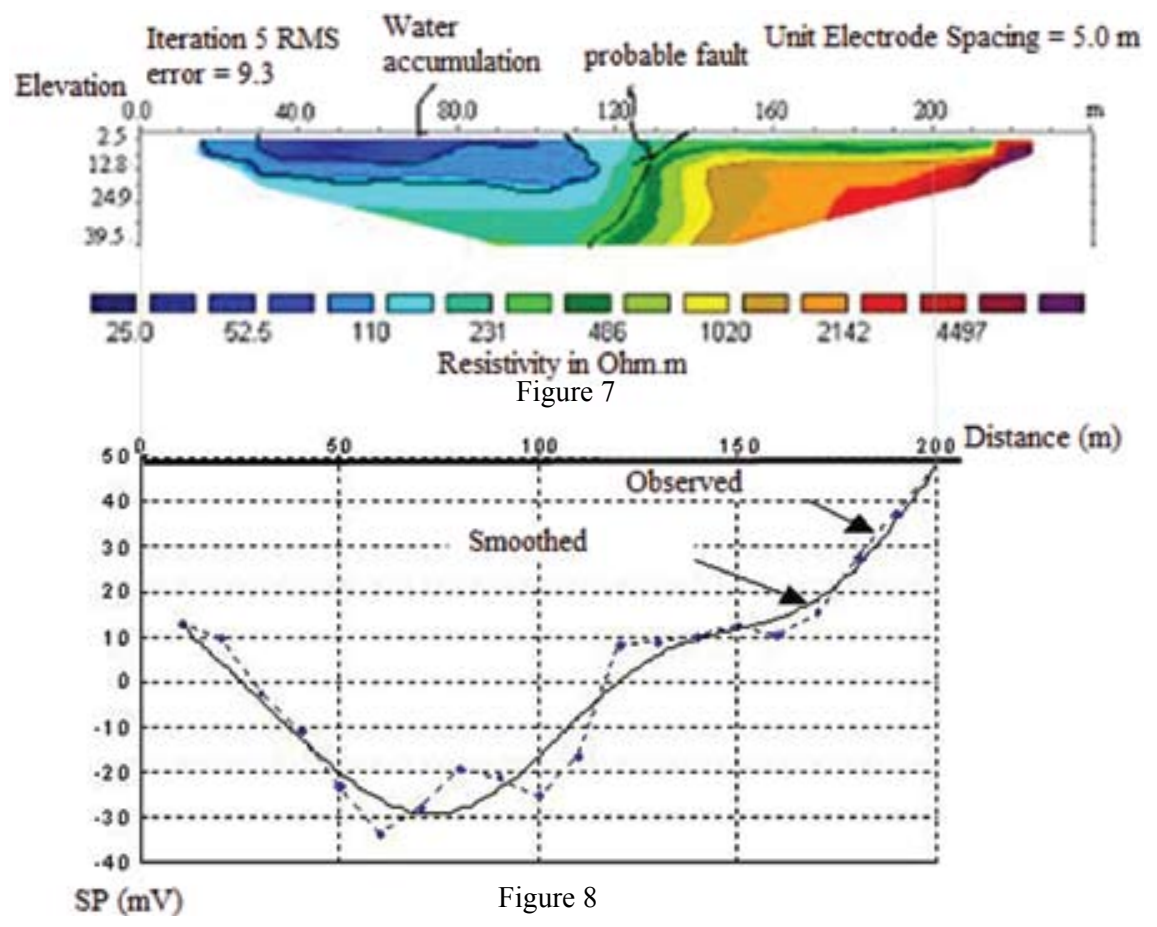

Figures 7 and 8: Resistivity image and SP survey profile respectively for transect $\mathrm{W}_{4} \mathrm{~W}_{3}$ 


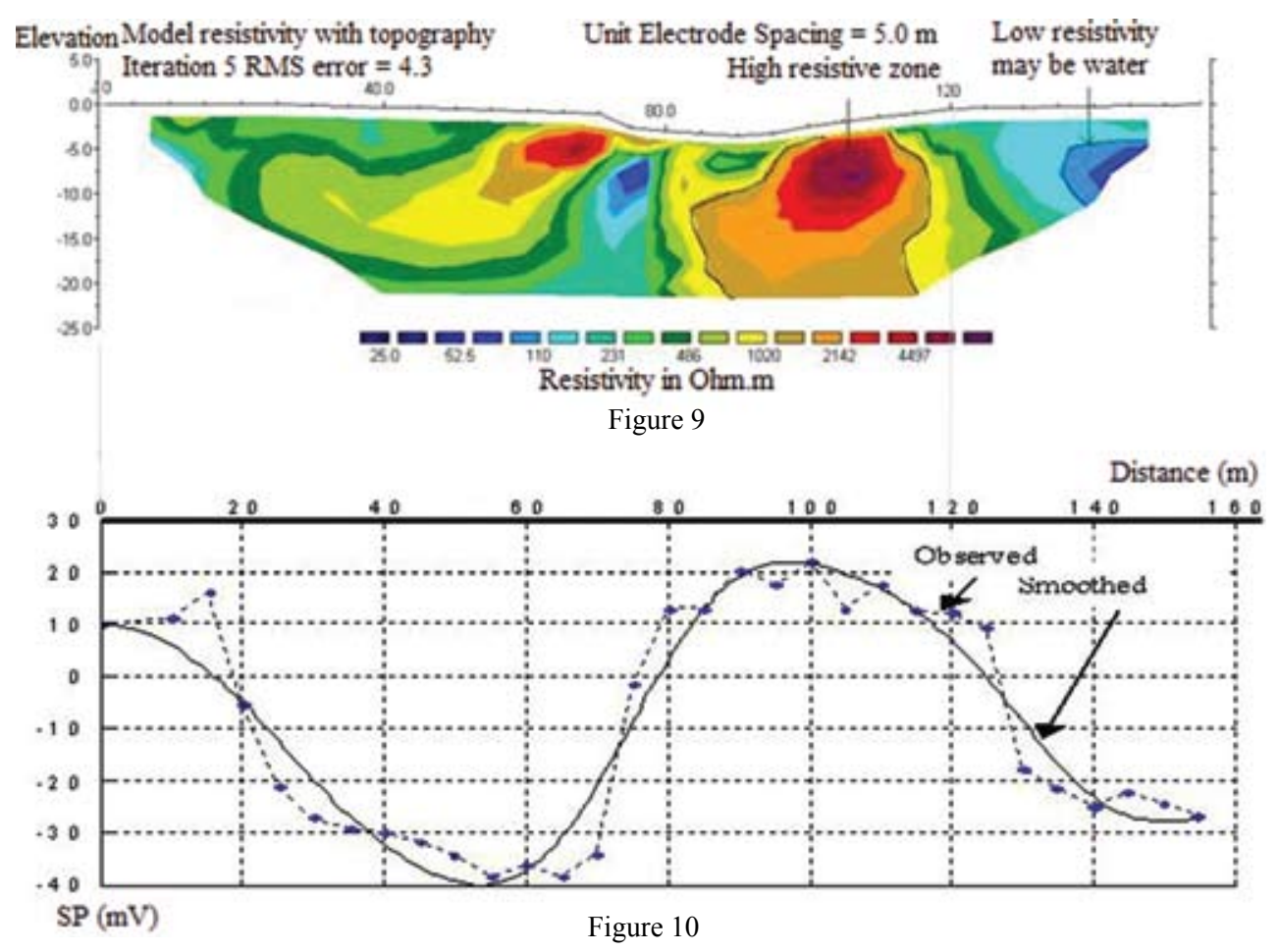

Figures 9 and 10: Resistivity image and SP survey profile respectively for transect $\mathrm{T}_{5} \mathrm{~W}_{1}$

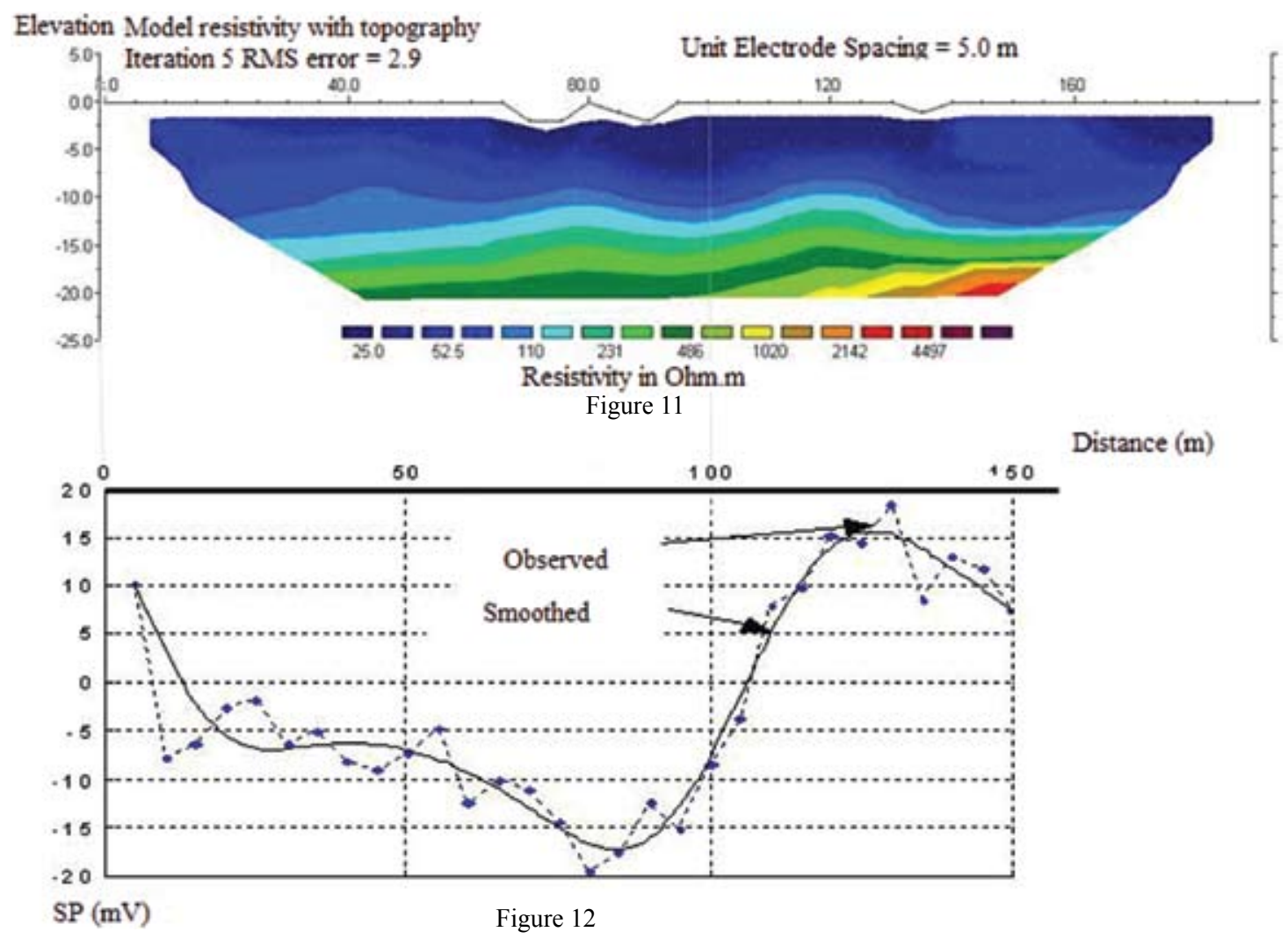

Figures 11 and 12: Resistivity image and SP survey profile respectively for transect $\mathrm{T}_{5} \mathrm{~W}_{2}$ 
There is no evidence for significant geological structures for the transect $\mathrm{T}_{5} \mathrm{~W}_{2}$. As such, groundwater in this area is likely to accumulate in the top soil layer and not in deep geological structures. This was evident during field inspection of existing wells in this area where they indicated that the water table was less than one metre from the surface. The negative SP anomalies for most of the profile (Figure 12) correspond well with these results. However, the rather high SP anomaly at a distance of about $125 \mathrm{~m}$ does not agree with those of the resistivity survey.

The resistivity profile (Figure 13) and SP anomalies (Figure 14) for transect $\mathrm{S}_{7} \mathrm{~W}_{1}$ indicate areas of low resistivity and negative SP anomalies respectively, thus indicating possible shallow groundwater accumulations. The resistivity image seems to indicate a possible fault at a depth of around $15-20 \mathrm{~m}$, which is not reflected in the SP values.

Figures $15 \& 16$ show the resistivity image and SP anomalies for transect $\mathrm{S}_{7} \mathrm{~W}_{2}$ respectively. As can be seen no significant geological structures are indicated on the resistivity image indicating the unlikely occurrence of structures for groundwater accumulations, which are also seen from the SP anomalies as they are mostly positive for the whole transect.

Figures 17 and 18 also show good correlation of results obtained by the two methods for transect $\mathrm{S}_{7} \mathrm{~W}_{4}$ as the low resistivity areas in the resistivity images overlap well with the areas of negative SP anomalies (indicated by $\mathrm{P}$ and $\mathrm{Q}$ in Figure 18), indicating possible groundwater accumulations. A fault or a weak zone can also be identified from the resistivity image.

Table 1 presents a summary of the results presented in detail, and an attempt was made to validate these results using field observations. As seen, there is good correlation with the results obtained with both resistivity imaging and SP anomalies with these general field observations.

Financial and other constraints restricted the study to the identification of these possible locations where groundwater is likely to be encountered without confirmation of the results by drilling or otherwise. Nevertheless, dug wells and other tube wells seen in areas identified as possible locations by the resistivity imaging and self potential methods, indirectly confirmed the results of the study as mentioned in Table 1 .

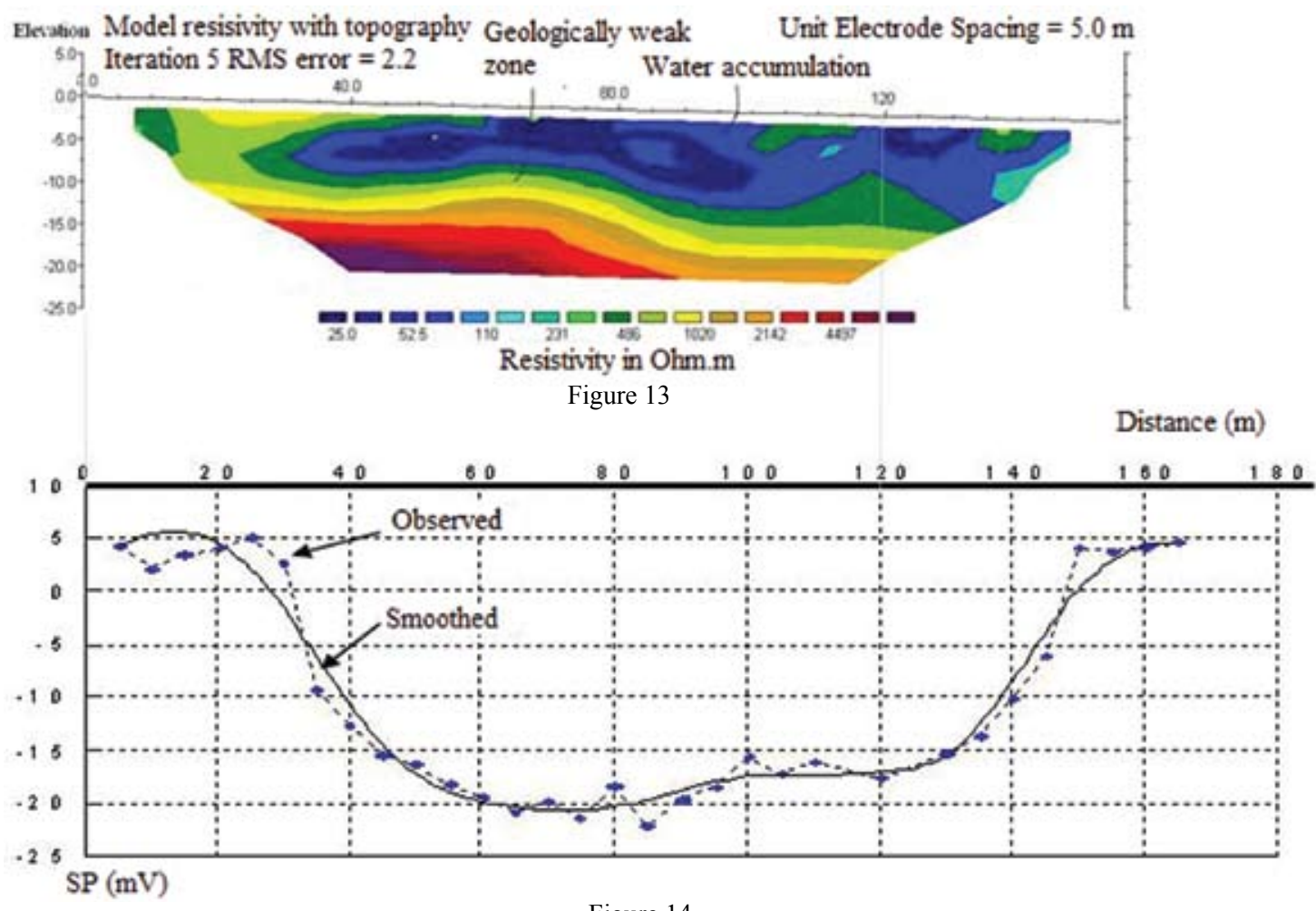

Figure 14

Figures 13 and 14: Resistivity image and SP survey profile respectively for transect $\mathrm{S}_{7} \mathrm{~W}_{1}$ 


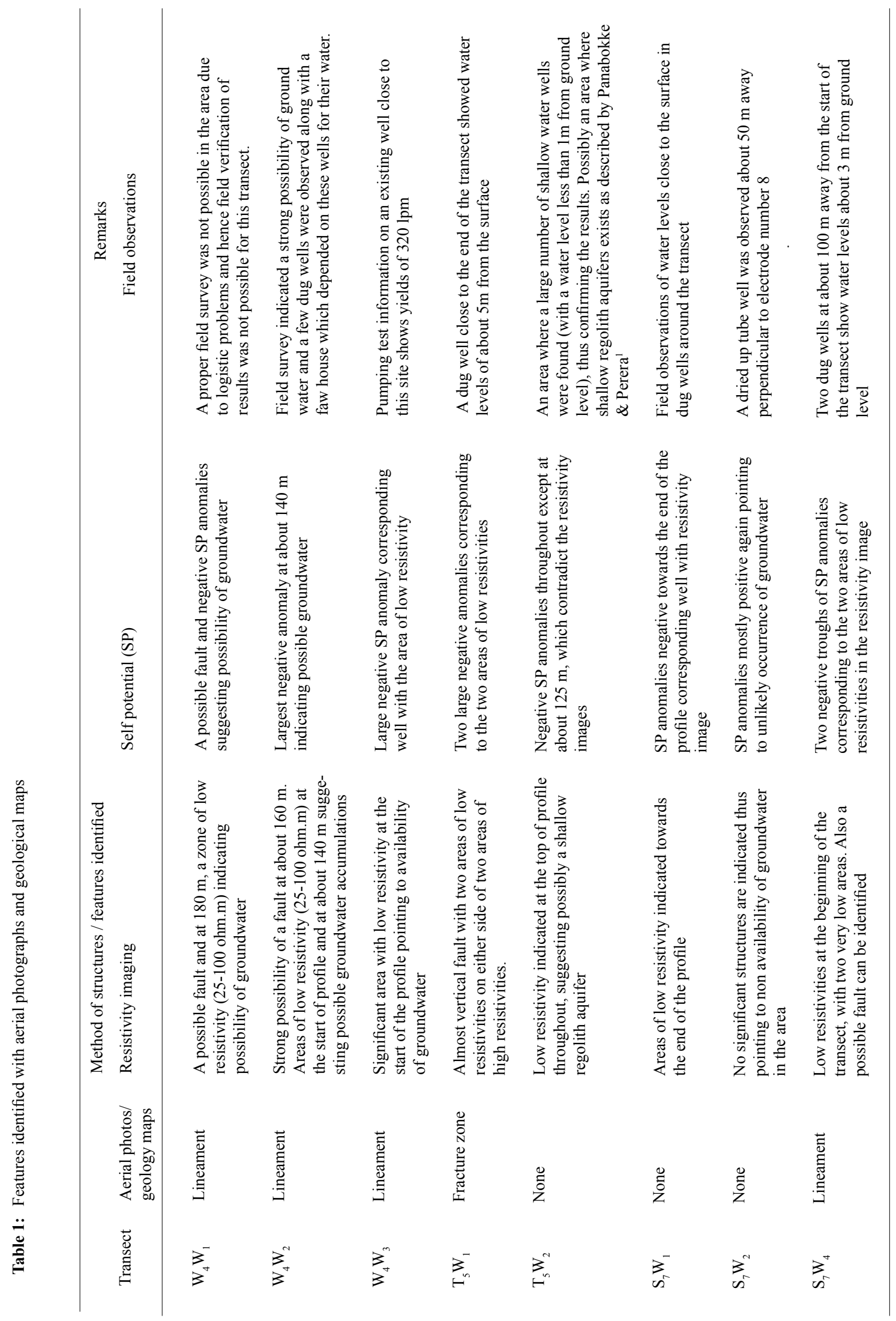




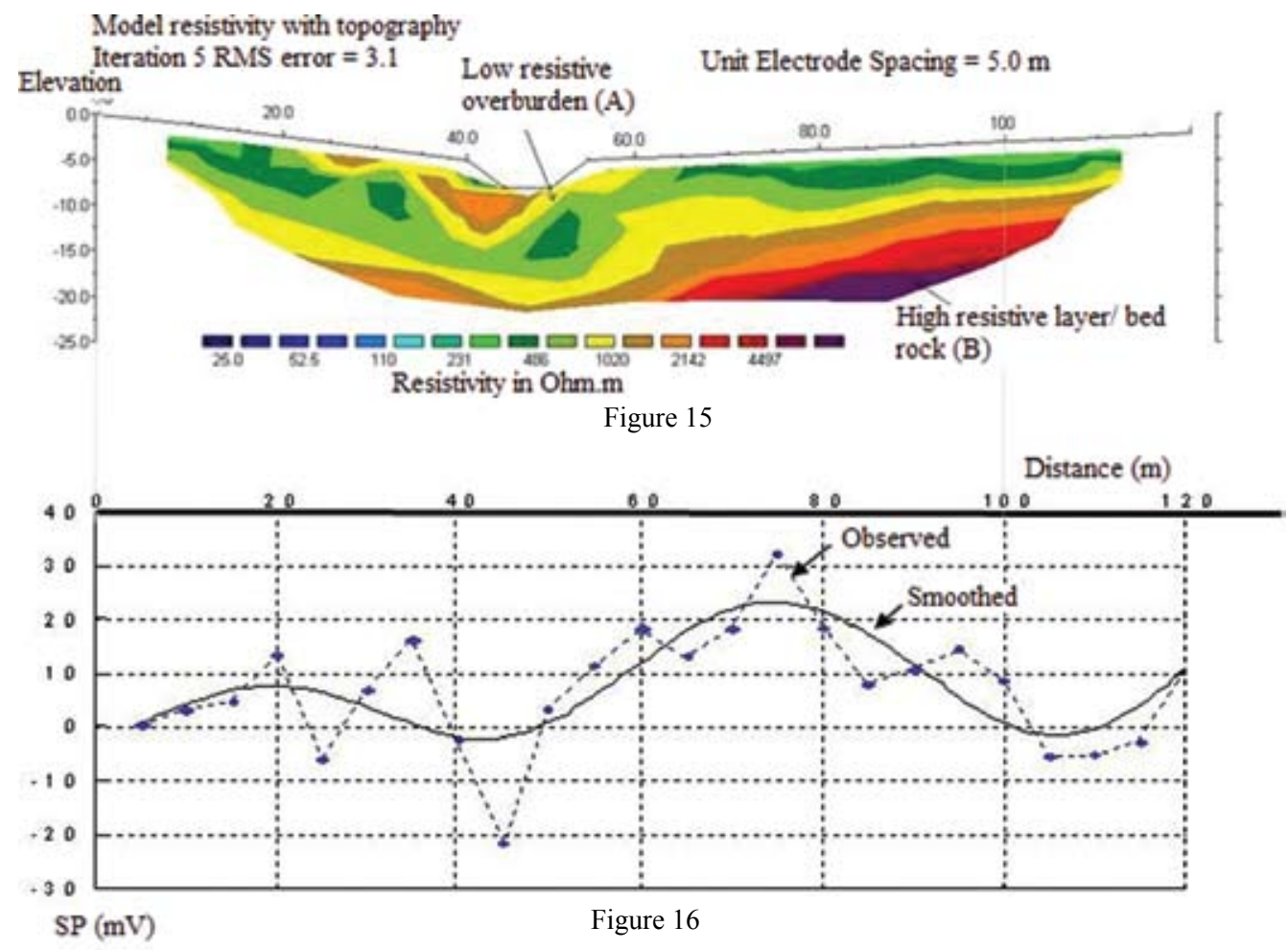

Figures 15 and 16: Resistivity image and SP survey profile respectively for transect $\mathrm{S}_{7} \mathrm{~W}_{2}$

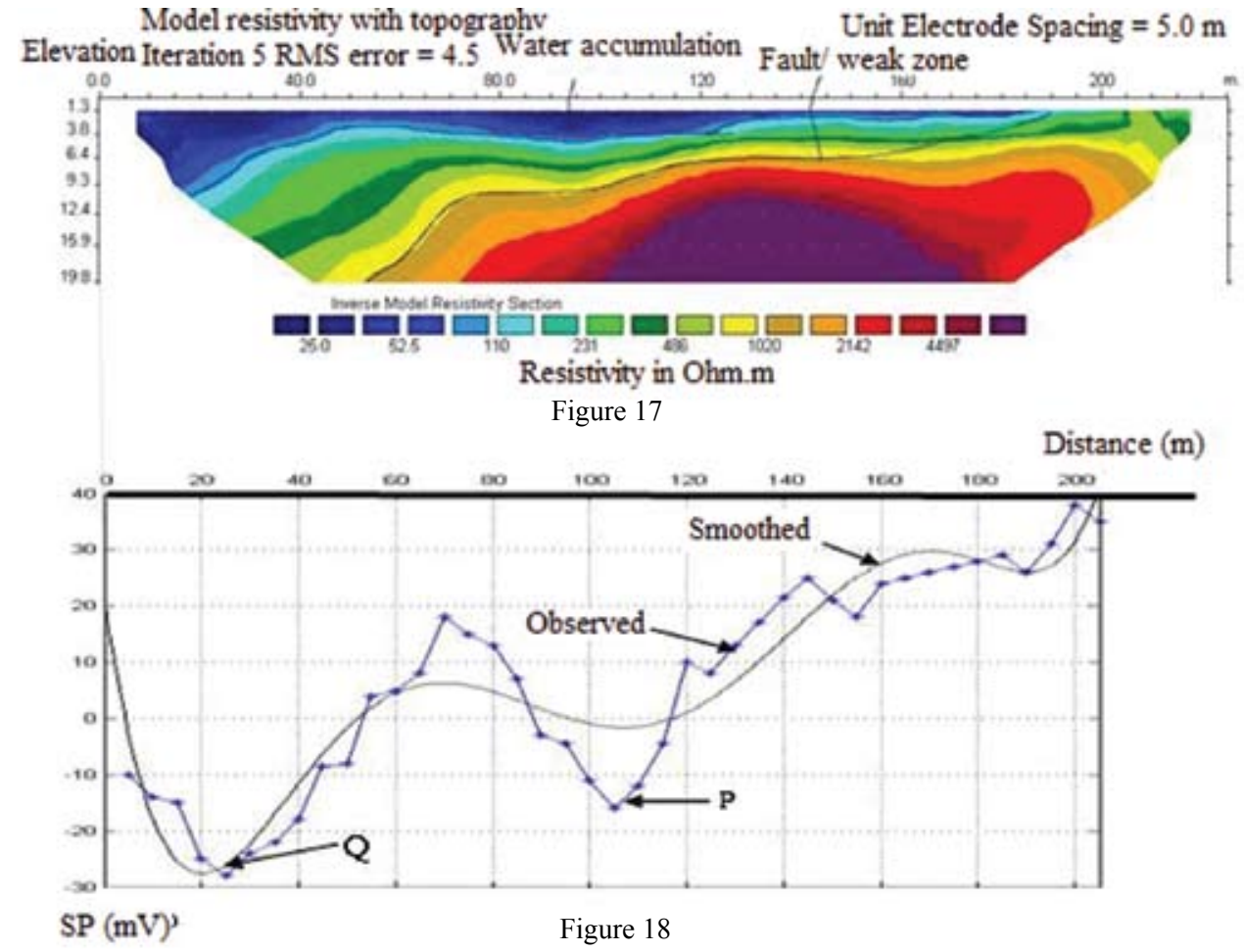

Figures 17 and 18: Resistivity image and $\mathrm{SP}$ survey profile respectively for transect $\mathrm{S}_{7} \mathrm{~W}_{4}$ 


\section{CONCLUSIONS}

The results point to a good correlation between the three methods used to identify geological structures or areas of possible accumulation of groundwater. Resistivity imaging and self potential methods show a lot of promise for prospecting of groundwater accumulations in the crystalline rock areas of the dry zone. These methods used with aerial photographs and geological maps will improve the accuracy of locating groundwater wells which are both productive and sustainable. When compared to the common practice in Sri Lanka at present to identify water bearing formations with a combination of resistivity surveys (with no imaging) and geological / structural maps and the reported accuracy is rather low as explained by many engineers from the National Water Supply and Drainage Board (NWSDB) and the Water Resource Board (personal communication). However, more work is needed before it can be put to practical use, which as explained could not be done in the present study due to many constraints beyond the control of the authors.

\section{Acknowledgement}

The study is part of a wider study carried out by the first author for the award of the M.Phil. degree. The contributions of Dr G.M. Fonseka and Dr Deepal Subasinghe are gratefully acknowledged. Also, the authors would like to extend their thanks to Dr Bruce Hobbs, University of Edinburgh, UK, for making arrangements and providing the necessary survey grants and equipments to carry out field work of the study. Further thanks are due to the Department of Physics of the Open University of Sri Lanka and the Department of Geology and Geophysics, University of Edinburgh, UK, for assistance in numerous ways.

\section{References}

1. Panabokke C.R. \& Perera A.P.G.R.L. (2005). Groundwater Resources of Sri Lanka Water Resources Board, 2A, Gregory's Avenue, Colombo.

2. de Silva R.P. (2001). Estimating groundwater recharge in the dry zone of Sri Lanka with a soil water budget model. II. Application of the Model to Estimate Recharge in Different Locations in the Dry Zone. Journal of Applied Hydrology XIV (2 \& 3): $22-35$.

3. de Silva R.P. (2002). Estimating Groundwater Recharge Using Chloride Ion as a Tracer: A Case Study in the Dry Zone of Sri Lanka, Journal of Applied Hydrology XV (2 \& 3): 91-99.

4. de Silva C.S. \& Weatherhead E.K. (1997). Optimising the dimensions of agro wells in hard-rock aquifers in Sri Lanka Agricultural Water Management 33. (2-3): 117-126.

5. Ramesam V. (1990). Quick quantitative appraisal of groundwater resources - case study on coconut triangle, Sri-Lanka. Journal of the Geological Society of India 35(5): 497-513.

6. Jayawardena U. de S. (2004). Sources of groundwater in crystalline hard rocks of Kandy area, Sri Lanka. Asian Journal of Water, Environment and Pollution 1 (1 \& 2) 119-122.

7. Powers C.J., Singha K. \& Haeni F.P. (1999). Integration of surface geophysical methods for fracture detection in bedrock of Mirror Lake, New Hampshire. U.S. Geological Survey Toxic Substances Hydrology Program-Proceedings of the Technical Meeting. Charleston, South Carolina, USA, 8-12, March 1999.

8. Griffiths D.H. \& Barker R.D. (1993). Two dimensional resistivity imaging and modeling in areas of complex geology. Journal of Applied Geophysics 29: 211-226.

9. Electrical imaging surveys for environmental and engineering studies, a practical guide to 2-D and 3-D surveys. http://www.abem.se. Accessed on 3 January 2008.

10. Telford W.M., Geldarl L.P. \& Sheriff R.E. (1990). Applied Geophysics. Cambridge University Press, UK.

11. Lowrie W. (1997). Fundamentals of Geophysics. Cambridge University Press, UK.

12. Meisner P. (1962). A method of qualitative interpretation of self potential measurements. Geophysics Prospecting 10(2): 203- 218.

13. Paul M.K. (1965). Direct interpretation of self-potential anomalies caused by inclined sheets of finite horizontal extension. Geophysics 30: 418- 423.

14. Self Potential Technique. http://www.nga.com/Geo_ser Self potential tech.htm. Accessed on 20 July 2008.

15. Colangelo G., Lapenna V., Perrone A., Piscitelli S. \& Telesca L. (2006). 2D Self-Potential tomographies for studying groundwater flows in the Varco d'Izzo landslide (Basilicata, southern Italy). Engineering Geology 88(3-4): 274-286.

16. Fonseka G.M. \& Jinadasa S.U.P. (1999). Multi-electrode geo-electric soundings: some applications in Sri Lanka. Annual technical sessions, Geological society of Sri Lanka,

17. Cooray P.G. (1984). The Geology of Sri Lanka (second edition). The Department of Government Printing, Colombo 08.

18. Mondel N.C., Rao V.A., Singh V.S. \& Sarwade D.V. (2008). Delineation of concealed lineaments using electrical resistivity imaging in granitic terrain. Current Science 94: 1023-1030.

19. Corwin R.F. \& Hoower B.D. (1979). The self potential method in geothermal exploration. Geophysics 44: 226245. 